\title{
Development of hierarchical commercial vehicle model for target cascading suspension design process
}

\author{
Kwang-chan Ko ${ }^{1} \quad$ Jong-chan Park $^{1} \quad$ Dae-oh Kang ${ }^{2} \quad$ Jae-hun Jo $^{3}$ \\ Min-su Hyun ${ }^{3}$ Seung-jin $\mathrm{Heo}^{3}$ \\ ${ }^{1}$ Hyundai Motor corporation, Korea, \{kcko, impactpack $\} @$ hyundai.com \\ ${ }^{2}$ Institute of Vehicle Engineering, Korea, bigfive@ivh.com \\ ${ }^{3}$ School of Automotive Engineering, Kookmin University, Korea, \{bluenice8,slay,sjheo\} @kookmin.ac.kr
}

\begin{abstract}
This paper presents the development of framework and an industrial application of commercial vehicle suspension \& steering system design based on the target cascading. This framework consists of 3 main modules, those are modeling, solving, and post-process module. Excel GUI is employed in order to give straightforward simulation way to the end users who are not familiar with vehicle dynamics simulation. End users are allowed to handle modeling parameters using Excel to build up models in the easy way. Key feature of solving module is that the simulation is conducted automatically with just selecting one of predefined scenario. The last module whose object is to calculate Ride and Handling performance index, is the post-process module.
\end{abstract}

A pilot study is applied to the practical issue to see the benefits of the framework, and design decision is made from the application results. This application study shows remarkable benefits not just in terms of Ride and Handling performance, but also in terms of solving cost. $15 \%$ of improved performance is produced regarding Ride and Handling, and $50 \%$ of development time is saved. It means that the framework allow to avoid timeconsuming process to achieve required target in the vehicle development process.

Keywords: Vehicle Dynamics, Target Cascadin g, Commercial Vehicle, Hierarchical Model, Suspension and Steering, Ride and Handling

\section{Introduction}

The framework development is explained from section 2 to section 4 . Section 2 contains the way of modeling and testing on the main sub-systems, and section 3 covers performance index calculator.

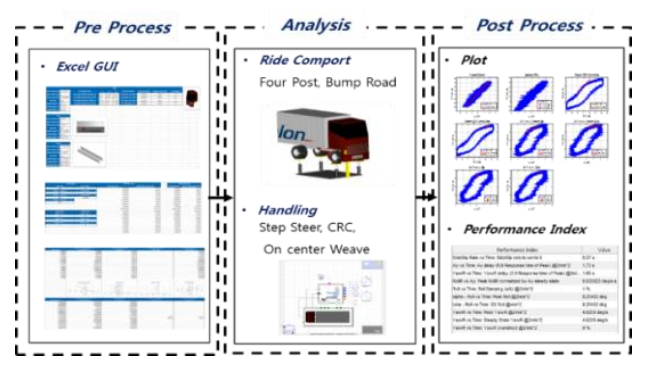

Figure 1. Overview of Frame Work

Section 4 is about the Excel interface development in order to give convenience to the end user. The optimization study is conducted to figure out the benefits of the developed framework in the section 5.

\section{Library Establishment of Vehicle Dynamics}

The main sub-systems of vehicle dynamics library consist of suspension, body, cab, and tire. For application to the target cascading process, each sub-system consists of geometrical and physical model.

\subsection{Suspension and Steering system}

\subsubsection{Suspension Modeling}

Full range of HMC commercial vehicle suspension types are modeled by using both Tubular Elastic Kinematic Suspension (TEKS) and Multi body Dynamics. TEKS use lookup table to specify suspension geometry, so TEKS model has to reflect the unique issue about commercial vehicle suspension. For instance, commercial vehicles have the suspension models of dependent type and independent type, the big difference between those suspension types is the roll motion. Generally in case of dependent suspension, left and the right movement is coupled in roll motion but the other is not. 
The number of suspension types using in commercial vehicles are quite large, for efficient approach, object-oriented methodology is taken into the Multi body dynamic modeling. Figure 2.1 shows the modeling results.

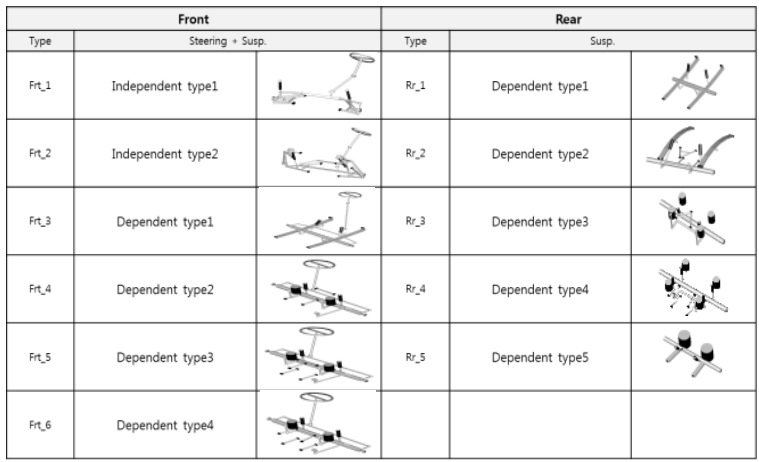

Figure 2.1 Multi Body Dynamic model

Force element of physical model was modeled from the functional equation that has the design variables as its factors. The parts developed by the method above are leaf spring, coil spring, air spring, stabilizer bar, etc. Table 2.1 show some examples of force elements.

Table 2.1 Leaf Spring Model

\begin{tabular}{|c|c|}
\hline Leaf Spring & 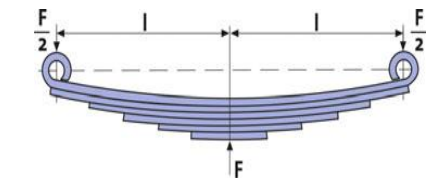 \\
\hline $\begin{array}{c}\text { Design } \\
\text { equation }\end{array}$ & $\begin{array}{c}c_{f}=\frac{E n w h^{3}}{2 K l^{3}} \\
K=\frac{3 n}{2 n+n_{-}} \\
n_{-}=n-1\end{array}$ \\
\hline parameter & $\begin{array}{l}E: \text { modulus elasticity } \\
n: \text { number of leaf } \\
w: \text { Leaf Width } \\
h: \text { Leaf thickness } \\
K: \text { Defection Factor } \\
l: \text { Leaf length } \\
n_{-}: \text {Modified number }\end{array}$ \\
\hline
\end{tabular}

We generate code of these functional equations in Modelica language like Figure 2.2.

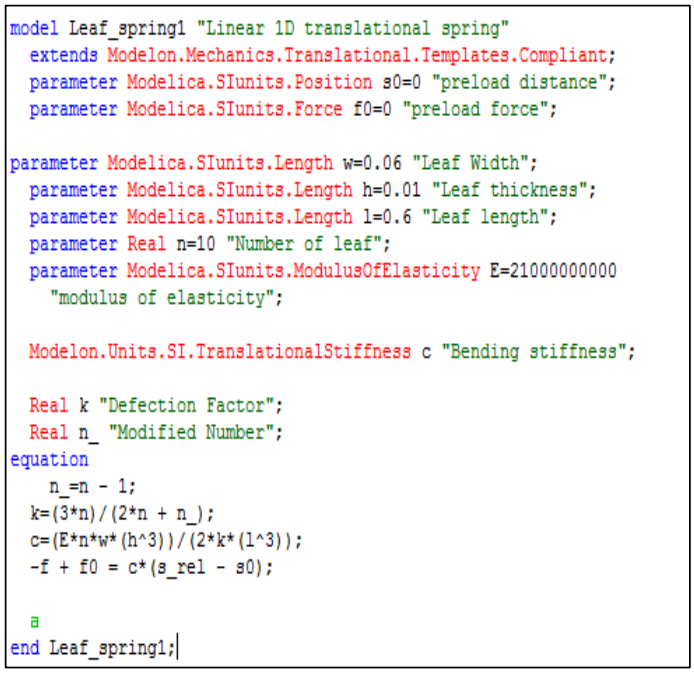

Figure 2.2. Leaf Spring Model (Modelica)

\subsubsection{Steering Modeling}

Once steering system is modeled. Rack\&Pinion steering is modeled for the independent suspension and Pitman-Arm steering is modeled for the dependent suspension.

Table 2.2 Rack\&Pinion, Pitman Arm Model

\begin{tabular}{|c|c|}
\hline Type & Steering \\
\hline $\begin{array}{c}\text { 1) Rack \& Pinion } \\
\text { (Independent) }\end{array}$ & \\
\hline $\begin{array}{c}\text { 2) Rack \& Pinion } \\
\text { (Dependent) }\end{array}$ & \\
\hline
\end{tabular}

\subsubsection{Validation}

Suspension models are validated by $\mathrm{K} \& \mathrm{C}$ experiment. Figure 2.3 show the comparison results of the established suspension system models of independent type and dependent type with the test data. From the comparison, we reach the conclusion that the established models have reliability. 

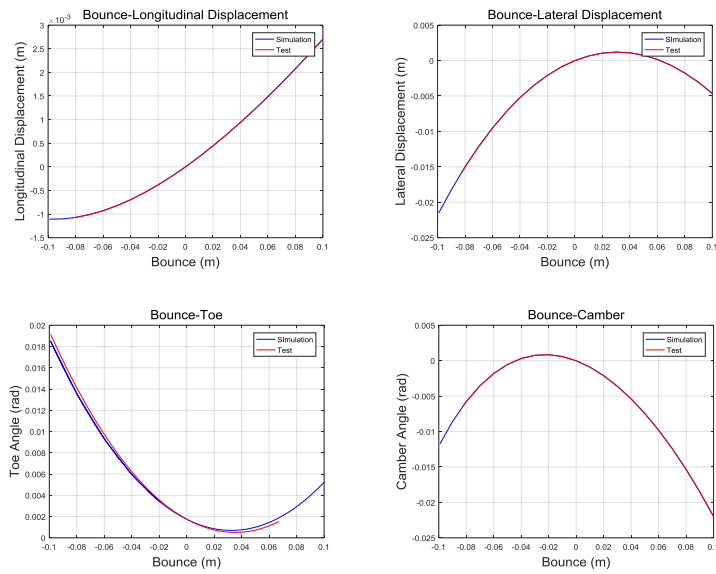

Figure 2.3. Parallel wheel travel

\subsection{Cab, Frame \& body Model}

3 types of Cabin mounting are used by HMC commercial vehicles are built up in the library as shown in table 2.3

Table 2.3 Cab Mounting library

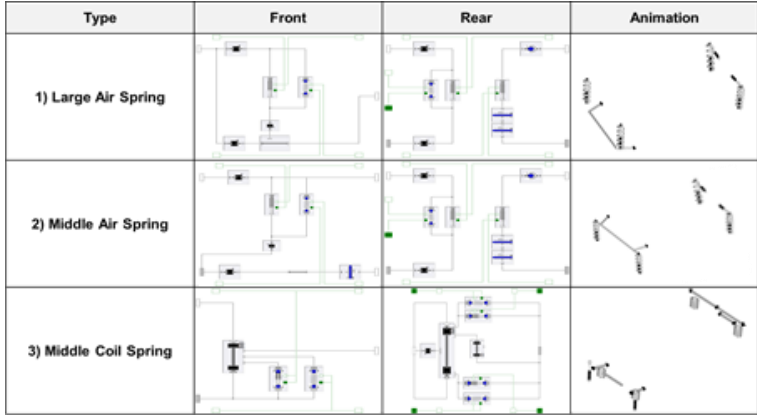

Lumped mass, C.G location, and moment of inertia are main input parameters in case of body model, but realistically bending and torsion can occur due to the long length of frame in the commercial vehicles, so bending stiffness and torsion stiffness to the lumped mass model are reflected.

\subsection{Tire model}

Pacejka 02 Tire are employed for tire library. In order to create reliable tire model, all the parameter that required for the Pacejka 02 are measured. Figure 2.4 is the description about one of the tire data.

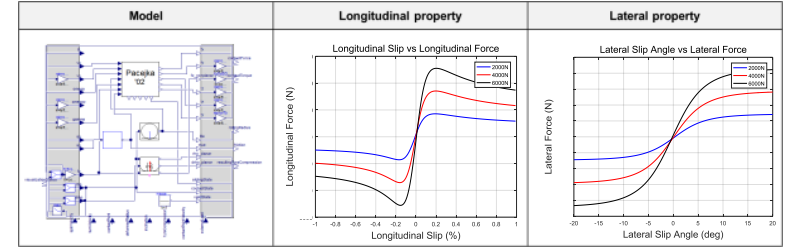

Figure 2.4. Pacejka 02 tire model

\section{Post Processor}

\subsection{Performance Index of R\&H}

The higher priority way to set up quantified $\mathrm{R} \& \mathrm{H}$ performance Index is from analysing statistical relationship between subjective feeling evaluation and objective measurement data, but a lot more valid sample data are demanded for the statistical relationship analysis. Realistically it is not easy to collect enough valid sample data due to many reasons. Instead of those preliminary researches, 3 benchmarking vehicles are chosen and measured to set up R\&H performance indexes in this stage.

(1) Test / simulation modes, measurement methods are established after 3 benchmarking vehicles are chosen with considering weight, wheelbase, and steering, suspension type. The specifications of 3 benchmarking vehicles are shown in Table 3.1.

Table 3.1 Specification of Benchmarking Vehicles

\begin{tabular}{|c|c|c|c|}
\hline & Vehicle A & Vehicle B & Vehicle C \\
\hline Wheel Base & 3,670 & 3,665 & 3,935 \\
\hline $\begin{array}{c}\text { Weight } \\
\text { (FRT/RR) }\end{array}$ & $\begin{array}{c}3,020 \\
(1,550 / 1,470)\end{array}$ & $\begin{array}{c}2,250 \\
(1,250 / 1,000)\end{array}$ & $\begin{array}{c}3,230 \\
(1,635 / 1,595)\end{array}$ \\
\hline Steering & Rack Pinion & Rack Pinion & Bell Crank \\
\hline $\begin{array}{c}\text { Front } \\
\text { Suspension }\end{array}$ & MacPherson Strut & MacPherson Strut & Double Wish Bone \\
\hline $\begin{array}{c}\text { Rear } \\
\text { Suspension }\end{array}$ & Rigid Axle & Rigid Axle & Rigid Axle \\
\hline
\end{tabular}

On-Centre Weave, Steady-State Cornering, Step Steer, Pulling Stability, Bumpy Ride are selected for test modes. Generally too many test / simulation modes cause a lot of solving cost in the optimization process, so test / simulation modes must be minimized.

(2) The 31 quantified indexes for $\mathrm{R} \& \mathrm{H}$ performance indexes are calculated using measurement data of benchmarking vehicles. Understeer gradient which decide cornering stability and Steering R2 value which decide cornering linearity are shown in Fig. 1 as examples 
of graphic calculation.

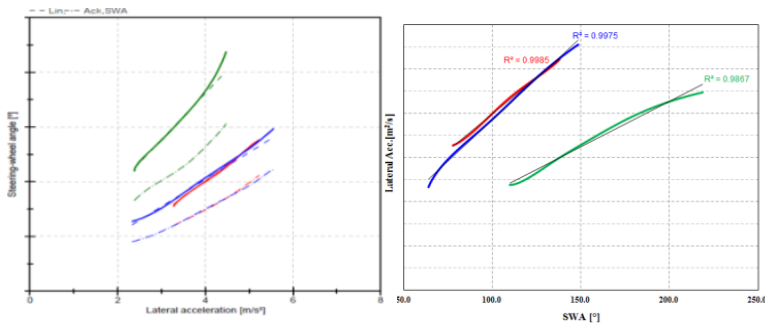

Figure 3.1. Steady-State Cornering Test

(3) The 31 quantified indexes are divided into 9 groups for mapping which represent subjective feeling. Those 9 groups consist of 3 controllability fields (Roll Control, Response Level, Cornering Controllability), 3 Stability fields (Understeer Balance, Response Velocity, Directional Stability), and 2 Steering Feel fields (Steering Sensitivity, Pulling), 1 Ride Comfort field (Bumpy Ride). Fig. 3.2 is example of the mapping results regarding Stability fields.

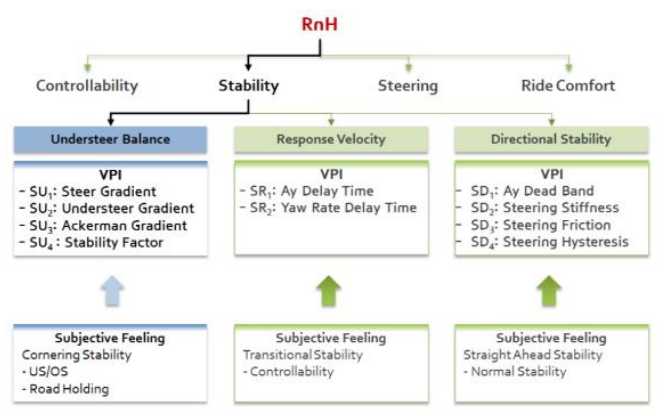

Figure 3.2. Stability Feeling Matching Map

(4) 31 indexes are taken into design of experiment (D.O.E) Screening to figure out the relationship between individual indexes of those 31 . Finally 24 indexes are selected after D.O.E Screening except 7 indexes which have repeated performance meaning by other indexes. The screening results are shown in Fig 3.3.

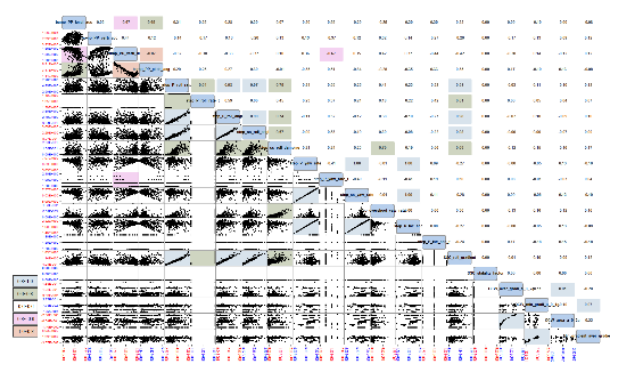

Figure 3.3. D.O.E Correlation of VPI
Table 3.2 Description of 24 Indexes

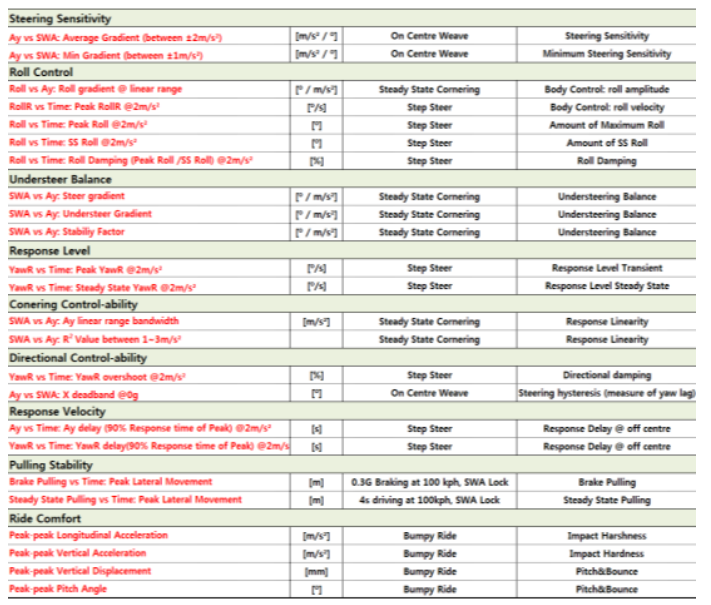

\subsection{Post-Processor}

To automate the performance index developed at 3.1 , post-processor was developed by using Matlab. The data used for the inputs in postprocessor comes from Dymola as mat-file form. Figure 3.4 is GUI of the post-processor.

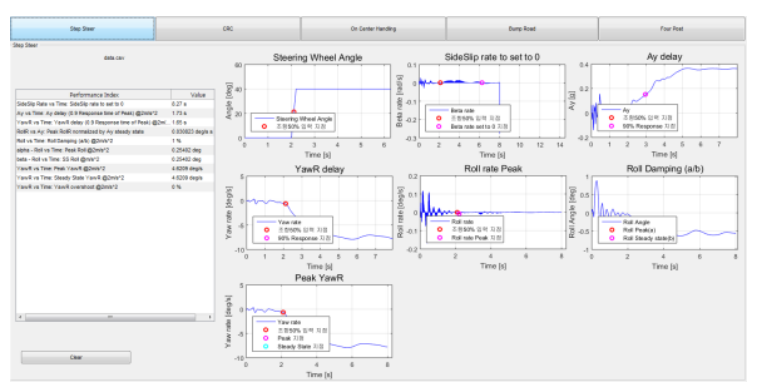

Figure 3.4. Performance index calculation program

\section{Modeling tool based on Excel.}

Pre-processing GUI is built based on Excel to give end users convenience. Like Figure 4.1, preprocessing is performed by inputting the model data first, and goes through the process that links the cells data inputted with the parameters on Modelica.

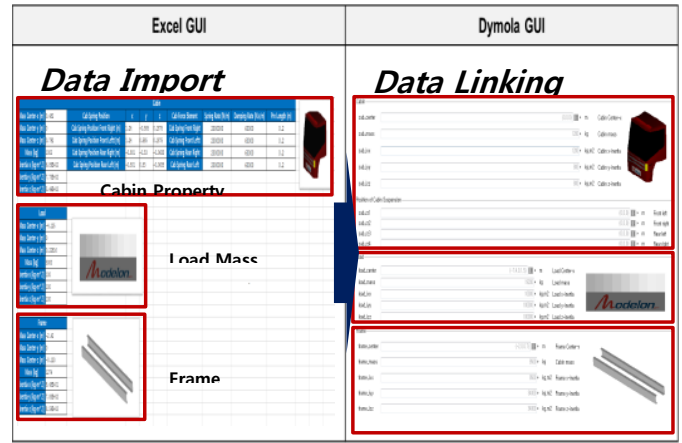

Figure 4.1. Parameter linking based on Excel 
Linking on Excel and Modelica parameters was processed by using the external data library which is one out of Modelica share libraries. Excel GUI is divided The constituted GUI is shown on Figure 4.2.

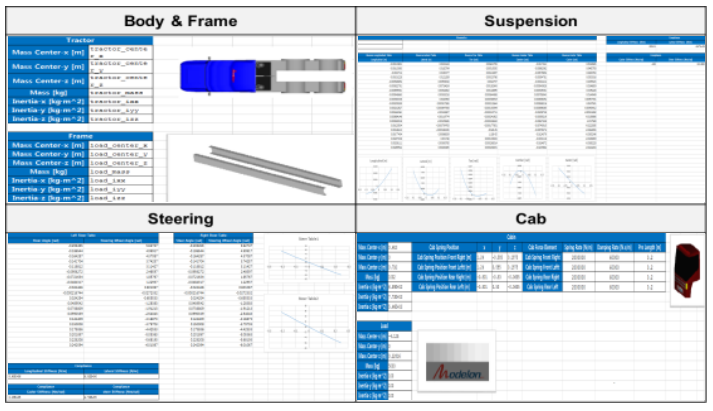

Figure 4.2. Excel GUI

\section{Application}

To review the validity of the simulation framework that was developed earlier, ride and handling performance simulation was conducted.

\subsection{Ride performance test}

\subsubsection{Model explanation}

Four-post test for the ride evaluation method are simulated, so the mulit body dynamics truck model waw combined with four-post test rig, and formed them as the test environment. The constituted truck chassis model was shown on Figure 5.1, and the four-post test environment was indicated on Figure 5.2.

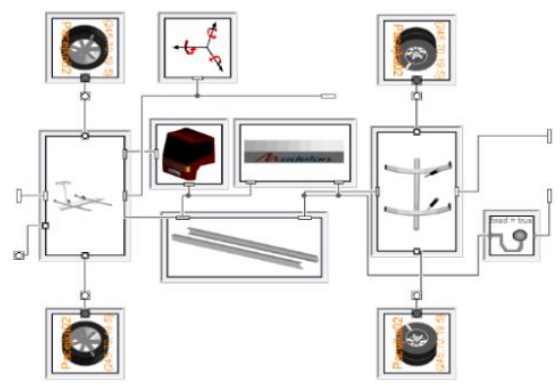

Figure 5.1. Truck Chassis Model

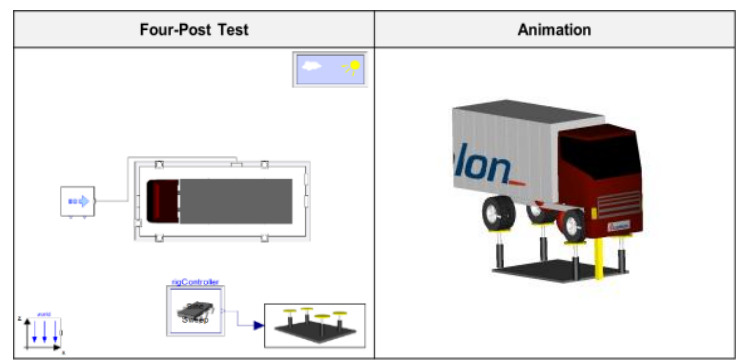

Figure 5.2. Four-Post Test Environment

\subsubsection{Explanation on the evaluation method.}

ISO C-Class road profile is used for the input of four-post test, and selected the vertical acceleration of body as performance index.

\subsubsection{Comparison analysis of the results}

As shown at Figure 5.3, the test results showed little error (RMS error: - \%) in time domain.

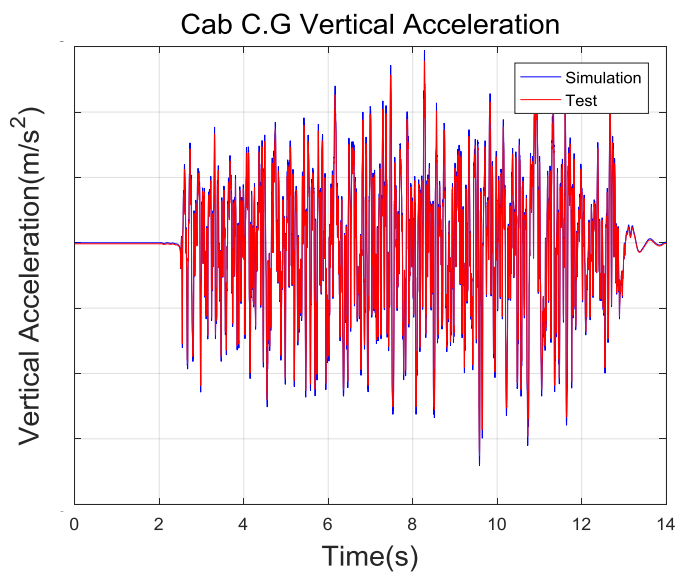

Figure 5.3. Four-Post Test Result Vertical Acceleration

Likewise, the gradient of PSD in frequency domain of Figure 5.4 was ilustraed with high accuracy as well.

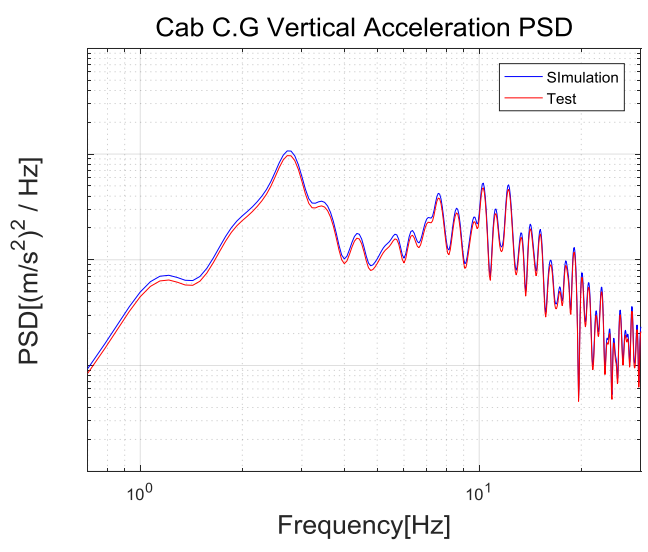

Figure 5.4. PSD

\subsection{Handling performance test}

\subsubsection{Model explanation}

CRC (Constant Radius Cornering) and step-steer maneuvers were taken into simulation to evaluate not just steady state condition but also transient condition response. The truck chassis model that used in ride test is linked with the steering 
controller which controls the vehicle to drive in a steady curvature, and the velocity controller which controls to drive as the speed allowed. The stepsteer test environment was established through combination of the steering actuator that controls to steer towards the allowed steering wheel angle and the velocity controller which controls to drive in steady speed shown as Figure 5.6.

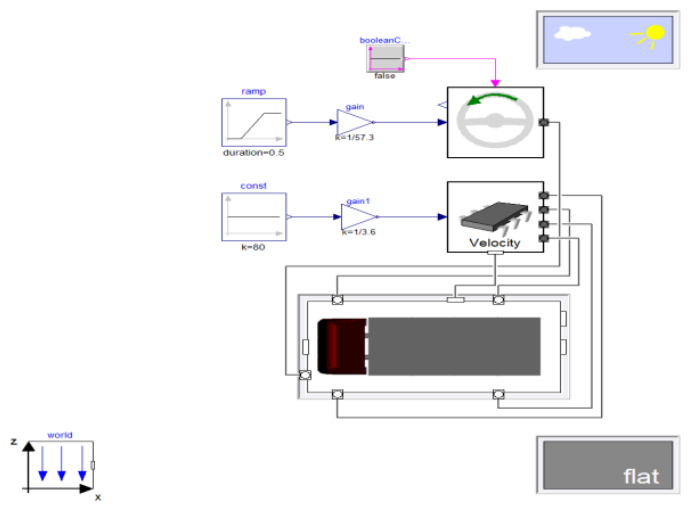

Figure 5.5. Step Steer Test Environment

\subsubsection{Comparison analysis of the results}

Figure 5.6 showed the gradient of steering wheel angle-lateral acceleration of $\mathrm{CRC}$, and it proves that this model predicts the steady state condition response of the truck in high accuracy. The performance index was estimated with little error as well.

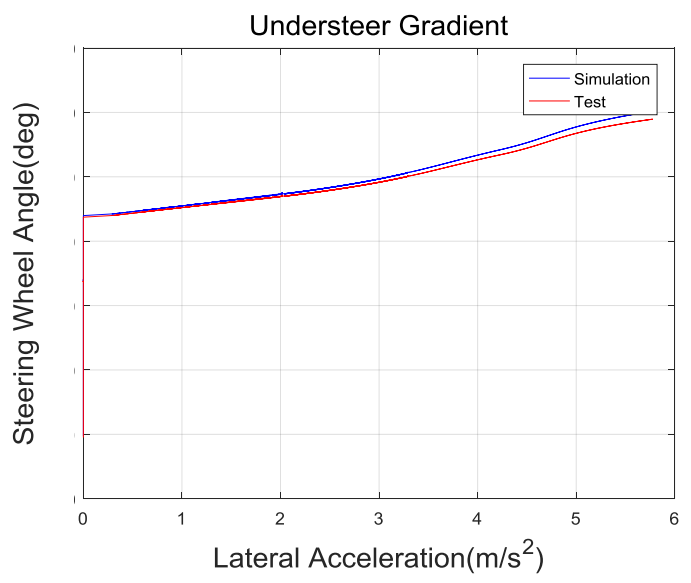

Figure 5.6. Understeer Gradient

Figure 5.7 showed the gradient of lateral acceleration of step-steer and yaw rate, and it proves that this model predicts the transient condition response in high accuracy. The performance index selected earlier was calculated with little error as well.
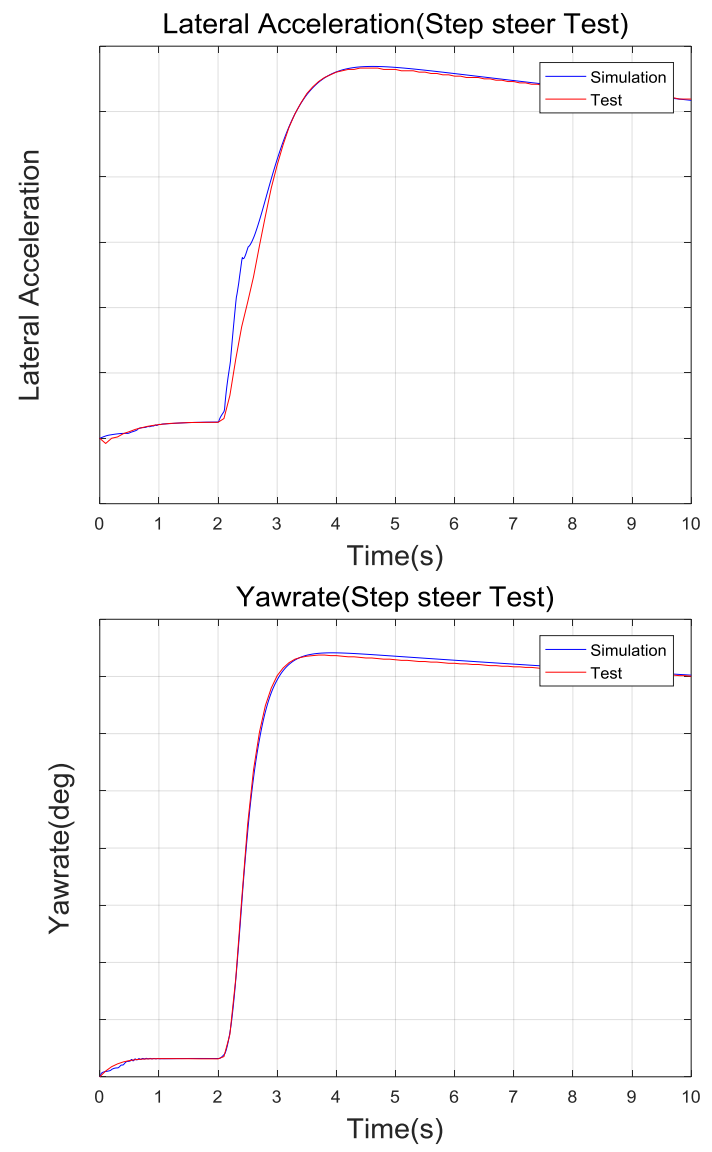

Figure 5.7. Lateral Acceleration, Yawrate

\subsection{Application of Target Cascading Design}

\subsubsection{Formulation of design matters}

For the application examples, RMS of body vertical acceleration, which is the ride performance index as the objective functions, is chosen, together with the parameters of air spring as the design variables. The matter was defined to find the design variable value to minimize the objective functions.

\subsubsection{System level design}

In system level, RMS of body vertical acceleration is extracted, and air spring property (F-D gradient) can be optimized through genetic algorithm in Optimization Library of Modelon. Genetic algorithm is a probability search algorithm, and it is favorable to the treatment for discrete variables, not influenced from the continuity and differentiability of functions, etc. which consist of the matters, and able to search globally. The formulation of design matters is the same as follows. 
Minimize $(x)=\sqrt{\frac{x_{1}+x_{2}+x_{3}+\cdots+x_{n}}{n}}$,

$x_{i}(i=1: n)=$ Body vertical acceleration,

$n=$ Number of data.

Subject to $0.8 y_{\text {base }}<y_{\text {base }}<1.2 y_{\text {base }}$

, $y_{\text {base }}=$ Air spring characteristic data of base model

Figure 5.8 shows the change of performance index, and Figure 5.9 indicates the property of the optimized design variables.

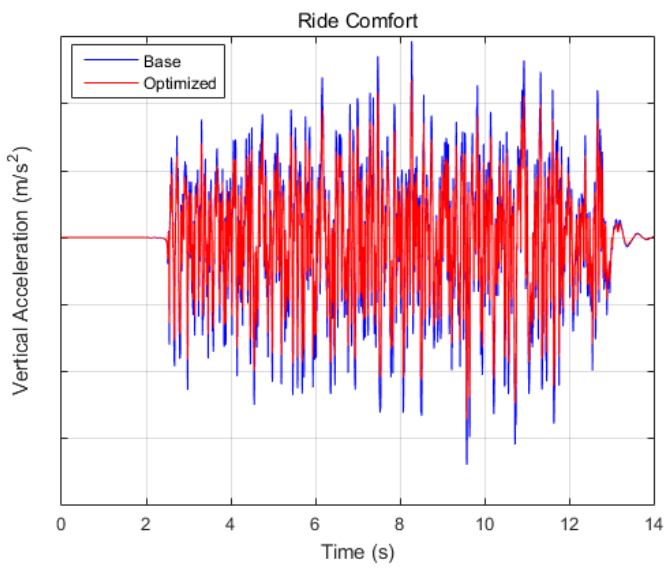

\begin{tabular}{|c|c|}
\hline \multicolumn{2}{|c|}{ RMS $\left(\mathrm{m} / \mathrm{s}^{2}\right)$} \\
\hline Base & 1.8410 \\
\hline Optimized & 1.4912 \\
\hline
\end{tabular}

Figure 5.8. Performance Index Variation

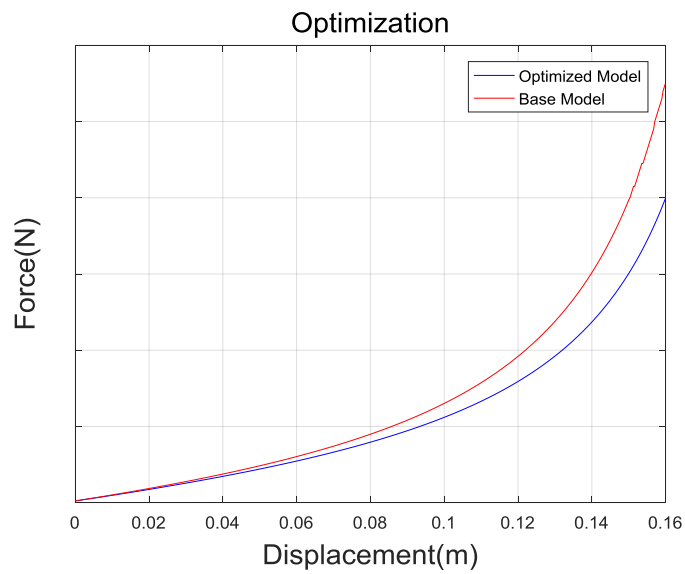

Figure 5.9. Optimization

\subsubsection{Sub-system level design}

In sub-system level, optimal value of parameters that can embody the optimized air spring derived from system-level through genetic algorithm is selected. The formulation of the optimized design is the same as follows.

Minimize $(x)=\sum_{i=1}^{n}\left(x_{s, i}-x_{s s, i}\right)^{2}$,

$x_{s, i}=$ System-level air spring data,

$x_{s s, i}=$ Subsystem-level air spring data,

$n=$ Number of data

Subject to $0.8 * y_{\text {base }}<y_{\text {base }}<1.2 * y_{\text {base }}$

, $y_{\text {base }}=$ Air spring parameters of base model

Figure 5.10 shows the comparison results between the property of air spring realized through the optimal parameters and the property of air spring derived from system-level, and we can see that the property value is embodied with little error.

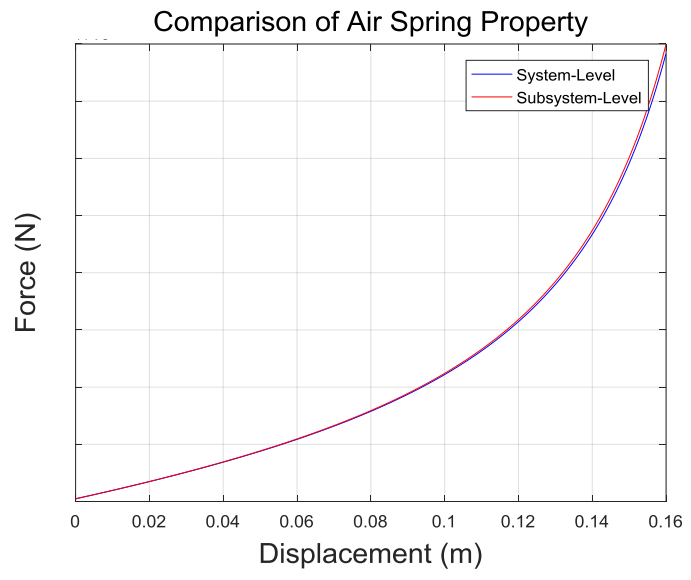

Figure 5.10. Comparison of Air Spring Property

Table 5.3 is one that compares the design variables of base model and the design variable values of the optimal model.

Table 5.1 Comparison of Air Spring Property

\begin{tabular}{|l|l|l|}
\hline & Base & Optimal \\
\hline $\begin{array}{l}\text { Nominal Preload } \\
\text { Force }\end{array}$ & $20000 \mathrm{~N}$ & $20000 \mathrm{~N}$ \\
\hline $\begin{array}{l}\text { Polytropic } \\
\text { Coefficient }\end{array}$ & 1.38 & 1.317 \\
\hline $\begin{array}{l}\text { Effective Area } \\
\text { with Respect to } \\
\text { Volume Area }\end{array}$ & $0.077 \mathrm{~m}^{\wedge} 3$ & $0.09343 \mathrm{~m}^{\wedge} 3$ \\
\hline $\begin{array}{l}\text { Effective Respect to } \\
\text { with Re } \\
\text { Load }\end{array}$ & $0.07315 \mathrm{~m}^{\wedge} 3$ & $0.0555 \mathrm{~m}^{\wedge} 3$ \\
\hline $\begin{array}{l}\text { Constant Pressure } \\
\text { Spring Rate }\end{array}$ & $1000000 \mathrm{~N} / \mathrm{m}$ & $1000000 \mathrm{~N} / \mathrm{m}$ \\
\hline
\end{tabular}




\section{Result}

Through this study, we developed the interpretation of hierarchical structure and the design model through object-oriented modeling method. The merits of constituted hierarchical structure model are as follows. Firstly, both behavior model and physical model can be interpreted at one platform. Secondly, design objectives and design variables that are indispensable for target cascading can be shared without separate treatment of data. Thirdly, it is easy for users, if necessary, to modify the model since the model has been established through object-oriented modeling method. And, to enhance design efficiency, we raised efficiency by developing design process through linking with pre-processor (Excel), model (Dymola), postprocessor (matlab). To test the effectiveness on this, we applied the established framework to the suspension system design matters that were considered to improve the performance of $\mathrm{R} \& \mathrm{H}$. From the result of design, we verified that performance improved by $15 \%$, and the time for design decreased more than $50 \%$ as well. These results proved that the developed framework is suitable for the suspension system design process of target cascading.

\section{Reference}

Kang, Ph.D: Robust Design Optimization Process Deve lopment for Suspension System by using Target Casca ding Method, Kookmin University, 2010.

J. Rauh: Virtual Development of Ride and Handling Ch aracteristics for Advanced Passenger Cars, J. Rauh, Vehi cle System Dynamics, vol. 40, no. 1-3, pp. 135-155, 2003. 